\title{
A STUDY ON SYNGAS PRODUCTION FROM DIFFERENT
}

\section{BIOMASS FEEDSTOCKS}

\author{
BEDEWIBILAL \& M. RAVIKUMAR \\ Department of Chemical Engineering, College of Engineering and Technology, \\ Samara University, Samara, Afar, Ethiopia
}

\begin{abstract}
The gasification process usually begins with the drying process, and then followed by pyrolysis. The pyrolysis process leads to breaking down of the biomass into solid matter, the gaseous mixture (mainly $\mathrm{CO}_{2}, \mathrm{CO} \mathrm{CH}_{4}$ and $\mathrm{H}_{2}$ ) and liquid matter. The main focus on biomass gasification process is to efficiently convert the entire char constituent into a gaseous product of the syngas by using either steam or $\mathrm{CO}_{2}$. The simulations include; gasification temperature, pressure, reactor volume, Equivalence ratio and moisture content have been investigated. From the result of sensitivity analysis increase the temperature the production of $\mathrm{H}_{2}$ and $\mathrm{CO}$ and the increase of moisture content of the biomass the lower heating value of the producer gas decrease. Based on the obtained result the maximum lower heating value of syngas was obtained at the gasification temperature of $800^{\circ} \mathrm{C}$, steam to biomass ratio of 0.1 , a pressure of 1 bar, 0.05 of moisture content and $0.02 \mathrm{~m}^{3}$ of reactor volume.

KEYWORDS: Biomass, Equivalence Ratio, Syngas, Pyrolysis
\end{abstract}

Received: Mar 14, 2018; Accepted: Apr 04, 2018; Published: Apr 28, 2018; Paper Id.: IJCPTJUN20182

\section{Introduction:}

Gasification is expected to be the future method of producing an energy carrier, and the production of syngas from biomass or waste would require gasification as an essential part of the overall process. Current Gasifiers can be classified into two types: fixed-bed gasifiers and fluidized-bed gasifier[1]. Biomass gasifiers are complex facilities, which make it difficult to investigate their various operating conditions. The characteristics of biomass greatly influence the performance of a biomass gasifier. A proper understanding of the physical and the chemical properties of biomass feedstock is essential for the design and operation of a biomass gasifier to be reliable. There are numerous models for biomass gasification has been developed. These models can be categorized into thermodynamic equilibrium models and kinetic models. The thermodynamic equilibrium models, also known as zero-dimensional models, are widely used among researchers to predict the composition of the produced syngas and the equilibrium temperature by assuming that the chemical reactions reach equilibrium. However, these models cannot provide highly accurate results and also cannot provide the concentration or temperature profiles inside the reactor. Kinetic models provide essential information on kinetic mechanisms to describe the chemical reactions involved in the biomass gasification, which is crucial in designing, evaluating and improving gasifiers. These models are based on the chemical reaction rates and are able to predict both overall and profiles of producer gas yield and compositions with time and location within the gasifier. However, as the models involve a number of reactions and transfer process, the models are computationally intensive [2]. Fluidized bed gasification is often adopted for a larger capacity of biomass feedstock. Fluidized bed gasification is more 
complicated in constructing and operating, and also requires a higher investment. For this study kinetic simulation of fixed bed gasification is chosen because of the suitability for any type of biomass and the lower investment cost requirements. Fixed bed gasification also has the advantage of a small amount of fly ash, and the syngas from biomass gasification can be used in various areas as clean energy[3]. Gasification is a thermochemical process that converts organic or fossil based carbonaceous material into a combustible gas by reacting the material under a certain range of temperature with a controlled/starved amount of air/oxygen often with a combination of steam. Biomass as a product of photosynthesis is one of the most abundant renewable resources that can be used for sustainable production of syngas (a mixture of $\mathrm{CO}$ and $\mathrm{H} 2$ ) [4]. The gasification process requires some gasifying agent that provides oxygen for the formation of $\mathrm{CO}$ from solid carbon in the fuel. The gasifying agents include air, oxygen, steam and CO2 [5]. The Present work focused effectively on syngas production from various feedstocks.

\section{MATERIALS AND METHODS}

\section{Biomass Feedstock Characterization}

The raw materials used in this study are agricultural residues (coffee bean husk and rice husk) locally produced in Ethiopia's farmlands. These materials were collected from farmlands and local community around Bahir Dar, Ethiopia. The chemistry of biomass gasification is similar to that of coal gasification and the general chemical formula used for the coffee bean husk and the rice husk was $\mathrm{CH} 1.76 \mathrm{O} 0.78 \mathrm{~N} 0.03$ and $\mathrm{CH} 1.64 \mathrm{O} 0.95 \mathrm{~N} 0.005$ respectively. Therefore, stoichiometric air required for complete oxidation of coffee bean husk and rice husk can be calculated from the reaction and $4.58 \mathrm{~kg}$ and $4.26 \mathrm{~kg}$ of air was required for complete combustion of $1.5 \mathrm{~kg}$ of coffee bean husk and rice husk respectively.

\section{Proximate Analysis}

A sample of each biomass is taken randomly and tested for proximate analysis to get the comprehensive details of biomass feed. Proximate analysis, which is a standardized procedure that gives an idea of the bulk components that make up a fuel, was done to determine the average of the percentage volatile matter, content, percentage ash content, moisture content and percentage, content of fixed carbon of the biomass obtained by using ASTM E872, ASTM D1102 and ASTM respectively.[6]

\section{Moisture Content (MC)}

The percentage moisture content (PMC) was found by weighing of the biomass sample (B0) and oven drying it at the temperature of $105^{\circ} \mathrm{C}$ until a constant weight of the sample (B1) was obtained. The loss in weight resulted in the amount of moisture present and sample left in the crucible is total solids present in the sample. The change in weight (B2) was then used to determine the sample's percentage moisture content by using the following equation:

$\mathbf{P M}=\mathbf{B} 2 / \mathrm{B} 0 \times 100$

\section{Volatile Matter (VM)}

The percentage volatile matter (PVM) was determined by pulverizing the oven-dried biomass sample in a crucible and placing it at $550 \square$ for 10 minutes in a Box type resistance furnace Model BK $-5-12 \mathrm{GJ}$ until a constant weight was obtained and weighed after cooling in desiccators.

The PVM was then calculated by using the following equation 


$$
P M C=\frac{\mathrm{B}_{0}-\mathrm{B}_{1}}{\mathrm{~B}_{0}} \times 100
$$

\section{Ash Content (AC)}

The percentage ash content (PAC) was also determined by heating oven-dried biomass samples in open silica crucible at $550^{\circ} \mathrm{C}$ for the minimum of 4 hours in Box type resistance furnace Model BK - 5 - 12GJ and weighed after cooling in a desiccator to obtain the weight of ash (C).

$$
\mathrm{PAC}=\frac{\mathrm{C}}{\mathrm{B}_{\mathbf{0}}} \times \mathbf{1 0 0}
$$

\section{Fixed Carbon}

The percentage fixed carbon (PFC) was computed by subtracting the sum of PVM and PAC from 100 as shown in the following equation:

\section{Fixed Carbon=100 \%-(PAC+PMC+PVM)}

\section{Ultimate Analysis}

This analysis is important for determining the elemental composition (C, N, H, S, O etc.) of the biomass fuels and the empirical formula of biomass as $\mathrm{C} n \mathrm{H} m \mathrm{O} x \mathrm{~N} y$ in order to establish a stoichiometric equation for the complete combustion of biomass and equivalence ratio for the gasification reaction. It was carried out by using EA 1112 Flash CHNS/O- analyzer. For the determination of elemental analysis of the biomass, the following condition was carried out, the Carrier gas flow rate of $120 \mathrm{ml} / \mathrm{min}$, reference flow rate $100 \mathrm{ml} / \mathrm{min}$, oxygen flow rate $250 \mathrm{ml} / \mathrm{min}$; furnace temperature of $900{ }^{\circ} \mathrm{C}$ and the oven temperature of $75^{\circ} \mathrm{C}$.

\section{Process Simulation Model Development}

In the area of process modeling and simulation, there are a number of processes modeling software packages available to develop computational models of gasification process and to perform simulation and validation studies. From those types of software packages, researchers and professionals use Aspen Plus, Computational Fluid Dynamics (CFD, composed of GAMBIT and FLUENT), Chem-CAD and Mat Lab to develop and optimize the gasification models. From the above mentioned software packages, Aspen Plus is one of the sophisticated processes modeling computer software packages which is familiar to many users and has proven its capacity for gasification model development and simulation [1]. It is a market leading comprehensive chemical process modeling tool, used by the world's leading chemistry organization and related industries. It originated from a joint called Advanced project System for Process Engineering (ASPEN) which is started by the Massachusetts Institute of Technology (MIT) and the US Department of engineering in the 1970's and finished in 1981. Aspen Tech was found in the same year and ASPEN project was commercialized Aspen Tech called Aspen Plus[7]Aspen Plus is used in the industrial chemical process modeling, simulation, optimization, sensitivity analysis and economic evaluation. It provides a comprehensive physical property model and the library of unit operation models, fast and reliable process simulation functions, and advanced calculation method. With the physical property database and the operation models provided by Aspen Plus, engineers are able to simulate actual plant behavior effectively and accurately, thereby improve the productivity and reduce the costs.[8]

Due to its reliability and precise outcomes in process modeling and simulation, Aspen Plus was used in this study to develop and simulate a fixed bed gasification process for coffee bean husk and rice husk as feedstocks. 
The simulations process was based on the mass-energy balance and chemical kinetics for the overall process. It comprises several databases containing physical, chemical and thermodynamic data for a wide variety of chemical compounds, as well as a selection of kinetic models required for the accurate simulation of any given system [9]

\section{Specifying Components}

In many types of simulation in Aspen Plus after flow sheeting, the process, specifying the necessary component is important to go the next process. In this fixed bed gasifier simulation process all the components were specified properly. Table 1 lists the components modeled in the simulation. Because the uncertainty of exact formulas of biomass and ash, they were defined as nonconventional solid components. For these components, only enthalpy and density were calculated during the simulation. Aspen Plus includes special models for estimating both enthalpy and density for coal-derived materials. These models can be used to estimate biomass properties as well as biomass can be considered as coal-derived material

Table 1: Detailed Data of the Components Modelled in the Simulation [1]

\begin{tabular}{|c|c|c|c|}
\hline Component ID & Type & Component Name & Formula \\
\hline BIOMASS & Nonconventional & & \\
\hline $\mathrm{ASH}$ & Nonconventional & & \\
\hline $\mathrm{C}$ & Solid & Carbon-Graphite & $\mathrm{C}$ \\
\hline $\mathrm{H}_{2}$ & Conventional & Hydrogen & $\mathrm{H}_{2}$ \\
\hline $\mathrm{N}_{2}$ & Conventional & Nitrogen & $\mathrm{N}_{2}$ \\
\hline $\mathrm{O}_{2}$ & Conventional & Oxygen & $\mathrm{O}_{2}$ \\
\hline $\mathrm{Cl}_{2}$ & Conventional & Chlorine & $\mathrm{Cl}_{2}$ \\
\hline $\mathrm{CO}$ & Conventional & Carbon-Monoxide & $\mathrm{CO}$ \\
\hline $\mathrm{CO}_{2}$ & Conventional & Carbon-Dioxide & $\mathrm{CO}_{2}$ \\
\hline $\mathrm{H}_{2} \mathrm{O}$ & Conventional & Water & $\mathrm{H}_{2} \mathrm{O}$ \\
\hline $\mathrm{CH}_{4}$ & Conventional & Methane & $\mathrm{CH}_{4}$ \\
\hline $\mathrm{S}$ & Conventional & Sulfur & $\mathrm{S}$ \\
\hline $\mathrm{SO}_{2}$ & Conventional & Sulfur-Dioxide & $\mathrm{O}_{2} \mathrm{~S}$ \\
\hline $\mathrm{NH}_{3}$ & Conventional & Ammonia & $\mathrm{NH}_{3}$ \\
\hline $\mathrm{H}_{2} \mathrm{~S}$ & Conventional & Hydrogen-Sulfide & $\mathrm{H}_{2} \mathrm{~S}$ \\
\hline $\mathrm{HCl}$ & Conventional & Hydrogen-Chloride & $\mathrm{HCl}$ \\
\hline
\end{tabular}

\section{Physical Property Method}

In this fixed bed gasifier simulation process, Redlich-Kwong-Soave cubic equation of state with Boston-Mathias alpha function property method was selected as the global property method for this model. It has been used to estimate all physical properties of the conventional components in the gasification process. This property method is comparable to the Peng Robinson cubic equation of state with the Boston-Mathias alpha function (PR-BM) property method. RKS-BM is recommended for gas-processing, refinery and petrochemical applications such as gas plants, crude towers and ethylene plants. This method is generally used for nonpolar or mildly polar mixtures, like hydrocarbons and light gases such as $\mathrm{CO} 2$, hydrogen sulfide and H2. Using RKS-BM, reasonable results can be expected at all temperatures and pressures. The RKS-BM property method is consistent with the critical region. The enthalpy and density model selected for both feed and ash is non-conventional components, HCOALGEN and DCOALIGT. In this study, the feed was defined as nonconventional components and the above model was selected during the simulation process. 


\section{RESULTS AND DISCUSSIONS}

\section{Effect of Temperature}

The temperature in the biomass gasification process is very important, since it is a parameter that can control gas composition, tar concentration, reaction rate and ash build-up, among others. Thus, it needs to be highly controlled.[10]low temperature gasification leads to high tar content and to low $\mathrm{CO}$ and $\mathrm{H} 2$ contents in the synthesis gas.[11]The LHV of syngas depends on the other operating parameters of the gasifier. As the gas composition is affected by temperature, this also significantly affects the LHV of the produced gas. The best way to get an LHV as high as possible is to produce a gas enriched in $\mathrm{CO}, \mathrm{CH} 4$, and $\mathrm{H} 2$ which could be suitable for energetic exploitation for instance in internal combustion engines and turbines for the production of power. The LHV of the gas has been calculated using the following equation[12].

$$
L H V=\left(10110 * X_{C O}+119494 * X_{H_{2}}+49915 * X_{C_{4}}\right) k J / k g
$$

Where $\mathrm{X}_{\mathrm{CO}}, \mathrm{X}_{\mathrm{H}_{2}}$ and $\mathrm{X}_{\mathrm{CH}_{4}}$ are the mole fraction of producer gas. The Lower Heating Value of the producer gas are LHVCO $=10,110 \mathrm{~kJ} / \mathrm{kg}, \mathrm{LHVCH} 4=49,915 \mathrm{~kJ} / \mathrm{kg}$ and LHV H2 $=11,949 \mathrm{~kJ} / \mathrm{kg}[13]$. As we observe from figure1 the increasing the temperature there is also increasing the heating value of the biomass feedstocks. The concentration of $\mathrm{H} 2$ whose coefficient within the above equation is the largest and this implies the increasing with temperature there is the increasing of $\mathrm{H} 2$ and $\mathrm{CO} 2$ concentration. At the lower concentration and the lower temperature, the heating value is increased fast. After some time later, both biomass heating value is increased slightly. Both biomasses have the reaches a maximum heating value at the temperature of $8000 \mathrm{C}$ and as the temperature increases the heating value are increasing slightly. As inspected from the following figure the rice husk has a heating value of $51,542.12 \mathrm{~kJ} / \mathrm{kg}$ and the coffee bean husk has $48,773.85 \mathrm{~kJ} / \mathrm{kg}$.

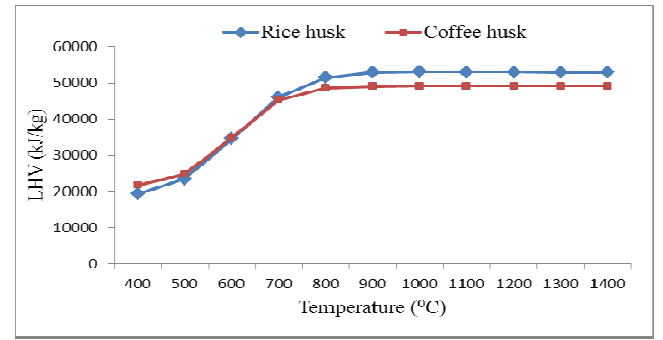

Figure 1: The Effects of Temperature on the Heating Value of Syngas

Table 2: Syngas Composition and LHV at Different Temperature of Coffee Bean Husk Biomass Mass Flow Rate $=1.5 \mathrm{~kg} / \mathrm{hr}$, Pressure $=1$ bar, ER $=0.2$

\begin{tabular}{|c|c|c|c|c|c|}
\hline $\begin{array}{c}\text { Temperature } \\
\left({ }^{(} \mathbf{C}\right)\end{array}$ & $\mathbf{C O}$ & $\mathbf{C O}_{\mathbf{2}}$ & $\mathbf{C H}_{\mathbf{4}}$ & $\mathbf{H}_{\mathbf{2}}$ & $\mathbf{L H V}(\mathbf{k J} / \mathbf{k g})$ \\
\hline 400 & 0.24672775 & 0.24672814 & 0.38057641 & 0.00276848 & 21821.71 \\
\hline 500 & 0.28560163 & 0.20814843 & 0.34170405 & 0.04116395 & 24862.44 \\
\hline 600 & 0.39646539 & 0.09817559 & 0.22324604 & 0.16577315 & 34960.49 \\
\hline 700 & 0.47551854 & 0.01987710 & 0.12166825 & 0.28864737 & 45372.19 \\
\hline 800 & 0.49379005 & 0.00181353 & 0.09289022 & 0.3275898 & 48773.85 \\
\hline 900 & 0.49546004 & 0.00016251 & 0.08980071 & 0.33206544 & 49171.33 \\
\hline 1000 & 0.49560235 & $2.0321 \mathrm{e}-05$ & 0.08949628 & 0.33253046 & 49213.14 \\
\hline 1100 & 0.49561854 & $3.2169 \mathrm{e}-06$ & 0.08945489 & 0.33259776 & 49219.28 \\
\hline 1200 & 0.49562033 & $7.4396 \mathrm{e}-07$ & 0.08944777 & 0.33261085 & 49220.51 \\
\hline
\end{tabular}




\begin{tabular}{|c|c|c|c|c|c|}
\hline \multicolumn{7}{|c|}{ Table 2: Contd., } \\
\hline 1300 & 0.4956201 & $1.5452 \mathrm{e}-07$ & 0.08944556 & 0.3326163 & 49221.05 \\
\hline 1400 & 0.49562015 & $5.9926 \mathrm{e}-08$ & 0.08944543 & 0.3326165 & 49221.06 \\
\hline
\end{tabular}

Table 3: Syngas Composition and LHV at Different Temperatureof Rice Husk

Biomass mass flow rate $=1.5 \mathrm{~kg} / \mathrm{hr}$, pressure $=1 \mathrm{bar}, \mathrm{ER}=0.2$

\begin{tabular}{|c|c|c|c|c|c|}
\hline $\begin{array}{c}\text { Temperature } \\
\mathbf{0}(\mathbf{0 C})\end{array}$ & $\mathbf{C O}$ & $\mathbf{C O 2}$ & $\mathbf{C H 4}$ & $\mathbf{H 2}$ & $\mathbf{L H V ( k J / k g )}$ \\
\hline 400 & 0.1418285 & 0.37042023 & 0.3450384 & 0.00561848 & 19327.85 \\
\hline 500 & 0.21577479 & 0.29563818 & 0.28673391 & 0.05948043 & 23601.36 \\
\hline 600 & 0.35846131 & 0.15113627 & 0.16072682 & 0.19302257 & 34711.76 \\
\hline 700 & 0.45724628 & 0.05082662 & 0.05564221 & 0.32461327 & 46189.48 \\
\hline 800 & 0.49032209 & 0.01713098 & 0.01334206 & 0.3842787 & 51542.12 \\
\hline 900 & 0.49828584 & 0.00900348 & 0.00238299 & 0.40034594 & 52995.55 \\
\hline 1000 & 0.50033098 & 0.00692664 & 0.00039237 & 0.40266814 & 53194.36 \\
\hline 1100 & 0.50128455 & 0.00596686 & $7.7279 \mathrm{e}-05$ & 0.40240728 & 53157.1 \\
\hline 1200 & 0.5019579 & 0.00529167 & $1.8884 \mathrm{e}-05$ & 0.40186311 & 53095.97 \\
\hline 1300 & 0.50248565 & 0.00476308 & $5.5551 \mathrm{e}-06$ & 0.40136533 & 53041.16 \\
\hline 1400 & 0.50291063 & 0.00433756 & $1.905 \mathrm{e}-06$ & 0.40094885 & 52995.5 \\
\hline
\end{tabular}

\section{Effect of Pressure}

A gasification pressure the methane concentration is also increasing and the result implies that the LHV of the syngas decreased as shown in figure 2 . The heating values of the biomass have been reaching a maximum at the lower pressure and decrease as the increasing of the pressure.

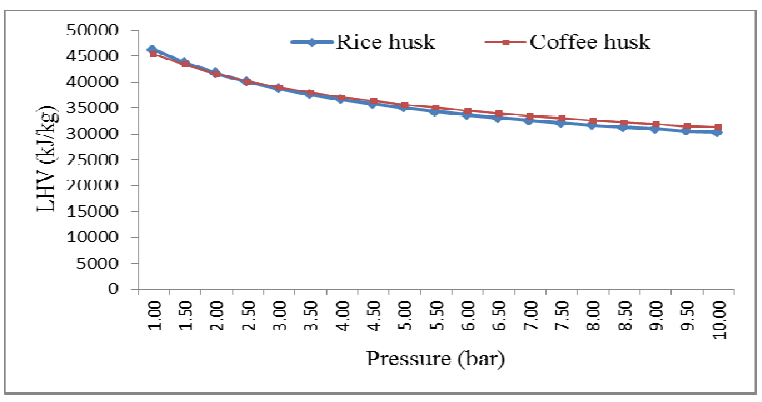

Figure 2: The Effect of Pressure on the Heating

Value of Syngas

Table 3: Syngas Composition and LHV at Different Pressure of Coffee Bean Husk Biomass mass flow rate $=1.5 \mathrm{~kg} / \mathrm{hr}$, temperature $=700^{\circ} \mathrm{C}, \mathrm{ER}=0.2$

\begin{tabular}{|c|c|c|c|c|c|}
\hline Pressure (bar) & CO & CO2 & CH4 & H2 & LHV(kJ/kg) \\
\hline 1 & 0.47551854 & 0.01987710 & 0.12166825 & 0.28864737 & 45372.19 \\
\hline 1.5 & 0.46395032 & 0.03131894 & 0.13939756 & 0.26496605 & 43310.42 \\
\hline 2 & 0.45389744 & 0.04126505 & 0.15434007 & 0.24531035 & 41605.9 \\
\hline 2.5 & 0.44515528 & 0.04991670 & 0.16699189 & 0.22889836 & 40187.9 \\
\hline 3 & 0.43747608 & 0.05751817 & 0.17784812 & 0.21499347 & 38990.6 \\
\hline 3.5 & 0.43065734 & 0.06426924 & 0.18728992 & 0.20304029 & 37964.62 \\
\hline 4 & 0.42454301 & 0.07032396 & 0.19560056 & 0.1926317 & 37073.86 \\
\hline 4.5 & 0.41901322 & 0.07580072 & 0.20299169 & 0.18346675 & 36291.73 \\
\hline 5 & 0.4139749 & 0.08079139 & 0.20962387 & 0.17531925 & 35598.26 \\
\hline 5.5 & 0.40935482 & 0.08536837 & 0.21562103 & 0.16801608 & 34978.21 \\
\hline
\end{tabular}


Table 4: Syngas Composition and LHV at Different Pressureof Rice Husk

Biomass mass flow rate $=1.5 \mathrm{~kg} / \mathrm{hr}$ temperature $=700^{\circ} \mathrm{C} \mathrm{ER}=0.2$ Moisture content $=0.05$

\begin{tabular}{|c|c|c|c|c|c|}
\hline Pressure (bar) & CO & CO2 & CH4 & H2 & LHV(kJ/kg) \\
\hline 1 & 0.45724628 & 0.05082662 & 0.05564221 & 0.32461327 & 46189.48 \\
\hline 1.5 & 0.44234329 & 0.06602055 & 0.07526588 & 0.2964882 & 43657.55 \\
\hline 2 & 0.43000707 & 0.07858988 & 0.09098246 & 0.27436321 & 41673.52 \\
\hline 2.5 & 0.41950916 & 0.08928077 & 0.10399077 & 0.25633819 & 40062.81 \\
\hline 3 & 0.41039039 & 0.09856323 & 0.11502289 & 0.2412671 & 38720.39 \\
\hline 3.5 & 0.40234365 & 0.10675144 & 0.12455561 & 0.22841168 & 37578.71 \\
\hline 4 & 0.39515359 & 0.11406557 & 0.13291555 & 0.21727108 & 36592.07 \\
\hline 4.5 & 0.38866342 & 0.12066586 & 0.14033565 & 0.20749137 & 35728.21 \\
\hline 5 & 0.38275547 & 0.12667254 & 0.14698746 & 0.19881404 & 34963.62 \\
\hline 5.5 & 0.3773392 & 0.13217806 & 0.15300077 & 0.19104506 & 34280.67 \\
\hline 6 & 0.37234344 & 0.13725507 & 0.15847597 & 0.18403547 & 33665.85 \\
\hline 6.5 & 0.36771129 & 0.14196166 & 0.16349221 & 0.17766865 & 33108.61 \\
\hline
\end{tabular}

\section{Effect of Equivalence Ratio, ER}

In the higher ER, the concentration of the syngas which is $\mathrm{CO}, \mathrm{H} 2$ and $\mathrm{CH} 4$ will be dominant as we examined from figure 3, the result shows as the increase of ER tends to the decrease of the energy content of the produced gas as shown in figure 3. The moisture content and the reactor volume are also other factors which influence the produced syngas.

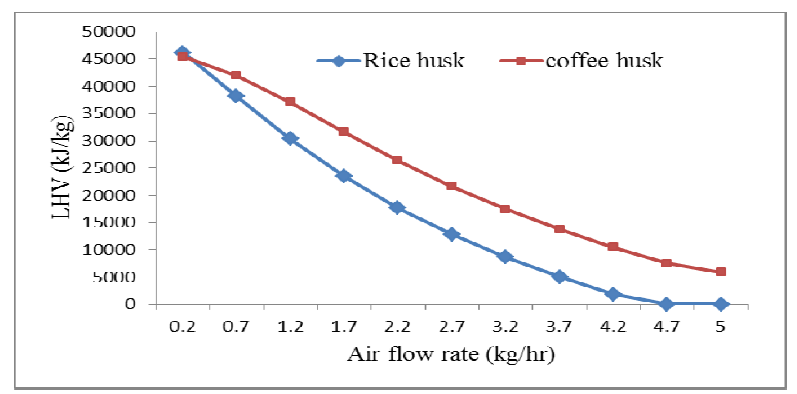

Figure 1: The Effect of ER on the Heating Value of Syngas

\section{Effect of Reactor Volume}

The increase of the reactor volume the composition of produced syngas $\mathrm{CO}, \mathrm{H} 2$ and $\mathrm{CH} 4$ also increased. As we observe from figure 4 the lower heating value of the produced syngas will increase as the increasing of reactor volume. As we surveyed from the following figure the coffee husk has a higher heating value as compared to that of the rice husk and have the value of $46,566.11 \mathrm{~kJ} / \mathrm{kg}$ for coffee husk and $42,455.84 \mathrm{~kJ} / \mathrm{kg}$ for rice husk at reactor volume of $0.4 \mathrm{~m} 3$. As observed from the simulation result the following conclusions are drawn. The concentration of syngas is increasing with increasing the gasification temperature and reactor volume. The concentration of combustible gas decreases with the increasing of temperature, reactor volume, air equivalence ratio and moisture content. But the increasing of the pressure results the concentration of methane gas is increased and the lower heating value of the syngas decreased. 


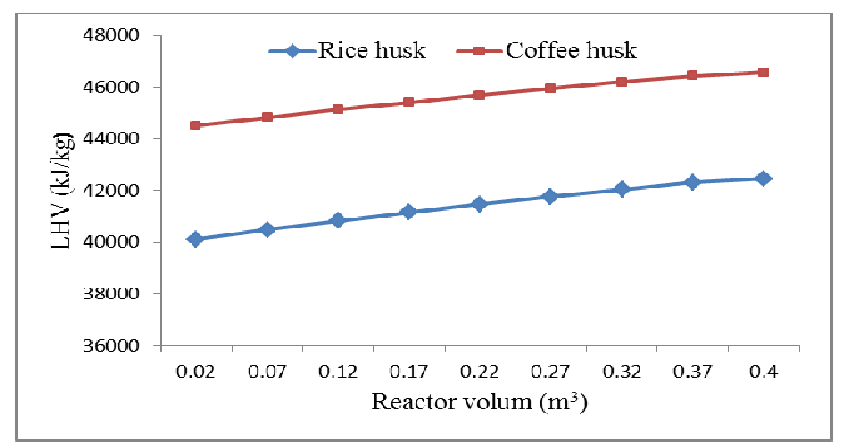

Figure Error! No text of specified style in document.: Effect of Reactor Volume on the LHV of the Syngas

\section{Effectof Steam}

As the ratio of steam to biomass increase and the lower heating value of the produced gas are decreased. At the lower steam to biomass ratio, the lower heating value of the biomass feedstocks used reaches its maximum value. The heating values of the biomass are decreased as shown in figure 5. We inspected that the coffee husk has the higher heating value of $46,192.6 \mathrm{~kJ} / \mathrm{kg}$ at the minimum steam to biomass ratio and also the rice husk has the higher heating value of $43,165.41 \mathrm{~kJ} / \mathrm{kg}$ at the same steam to biomass ratio with coffee husk. This implies that both biomasses have higher heating value at lower steam to biomass ratio. But the coffee bean husk has the higher heating value as compared to rice husk.

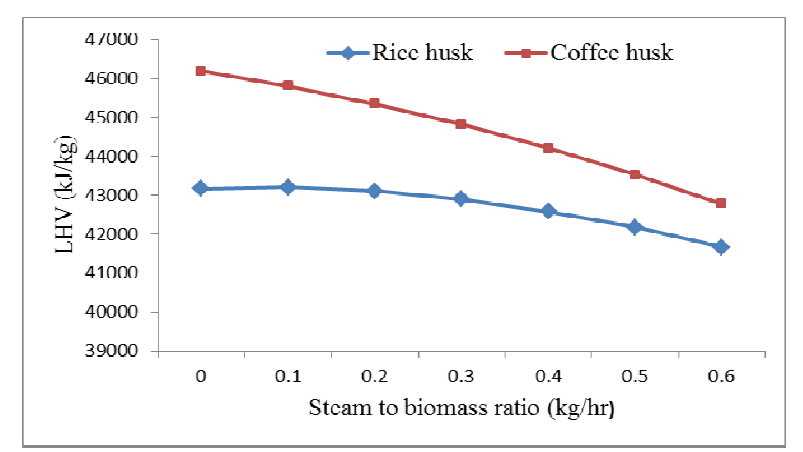

Figure 5: The Effect of Steam on the LHV of Syngas

\section{CONCLUSIONS}

In this project, the simulation of biomass gasification for syngas production in a fixed bed reactor was developed using the Aspen plus simulator. The effects of these parameters on the syngas composition, LHV of the syngas were studied. The higher gasification temperature increased the lower heating value, the heat conversion efficiency and carbon conversion. The effective temperature of the gasifier for the production of syngas should be $8000 \mathrm{C}$ at the air equivalent ratio of 0.2. The production of syngas is affected by another gasification operating parameter which is the air equivalent ratio. The higher air equivalent ratio increased the carbon conversion, while decreasing the lower heating value. At the smaller air equivalent ratio the lower heating value is maximum, and then decreased when the ratio increased. The lower air equivalent ratio implies the higher the concentration of producer gases and the higher of the syngas was obtained. 


\section{REFERENCES}

1. Ke, S., Optimization of biomass gasification reactor using Aspen Plus in Faculty of Technology 2014, Telemark University College Norway. p.76.

2. Sharma, A. K., Equilibrium and kinetic modeling of char reduction reactions in a downdraft biomass gasifier. A comparison. Solar Energy 2008. 82: p. 918-28.

3. Chen Chong, Y. J. -h. J. Y. -q., and C. Yong, Simulation of municipal solid waste gasification for syngas production in fixed bed reactors. Journal of Zhejiang University-Science and Applied Physics \&Engineering, 2010. 11(8): p. 619-628.

4. Chittaranjan, P., Aspen Plus Simulation And Experimental Studies on Biomass Gasification, in Chemical Engineering. 2012 , National Institute of Technology Rourkela. p. 39.

5. Schuster G., G. L., Weigl K., Hofbauer H., Biomass steam gasification an extensive parametric modeling study. Bioresource Technology, 2001.

6. R. S. Boone and E. M. Wengert, Guide for Using the Oven-Dry Method for Determining the Moisture Content of Wood 1998, University of WISCONSN-MADISON.

7. $\quad$ Sun L, Chemical Engineering Process Simulation using Aspen Plus. Chemical Industry Press 2012.: p. 326.

8. Process modelling tool for conceptual design, optimization, and performance monitoring of chemical processes [Internet]. Aspen Technology, Inc.

9. Zheng, L. F., and E, Aspen simulation of cogeneration plants. Energy Conversion and Management, 2003. 44: p. 184551[11]W. Xing, H. H. Ngo, S. H. Kim, W. S. Guo, P. Hagare; Bioresource Technology, 99, 8674-8678 (2008).

10. Taba L. E., et al., The effect of temperature on various parameters in coal, biomass and Co-gasification: a review. Renewable and Sustainable Energy Reviews 2012.16: p. 5584-96.

11. Gómez-Barea A, L. B., Perales AV, Nilsson S, Cano DF, Improving the performance of fluidized bed biomass/waste gasifiers for distributed electricity a new three stage gasification system. Applied Thermal Engineering, 2013.50: p. 1453-62.

12. Lv P. M., X. H., Chang J., Wu C. Z., Chen Y., Zhu J. X., An experimental study on biomass air-steam gasification in a fluidized bed. Bioresource Technology, 2004. 95: p. 95-101.

13. Lars Waldheim and Torbjörn Nilsson Heating Value of Gases from Biomass Gasification Report prepared for. 2001 , Task 20 Thermal Gasification of Biomass IEA Bioenergy Agreement. 
